\title{
The Eportfolio as Support for the Professional Development of Preservice Teachers: a Theoretical and Practical Overview
}

\author{
Thierry Karsenti, Gabriel Dumouchel, Simon Collin \\ Universiy of Montreal, Canada \\ Thierry.karsenti@umontreal.ca \\ University of Montreal, Canada \\ gabriel.dumouchel@umontreal.ca \\ University of Quebec in Montreal, Canada \\ collin.simon@uqam.ca
}

\begin{abstract}
The portfolio is rapidly gaining attention in initial teacher training programs. It serves multiple uses and ends in the professional development and reflective practice of preservice teachers, and the technical advances of Web 2.0 will only increase the potential for learning opportunities. From now on, portfolio content that was formerly private territory can be generously shared. Against this background, this article provides an overview of the portfolio's role in initial teacher training programs. The four main functions of the portfolio are addressed, followed by the advantages of the eportfolio over the paper portfolio. A working conceptual framework is then proposed for eportfolio use to support professional development in the Web 2.0 age. To provide a practical application for initial teacher training, we conclude with a presentation of Eduportfolio, an eportfolio that effectively taps the potential of Web 2.0.
\end{abstract}

\section{Council for Innovative Research}

Peer Review Research Publishing System

Journal: INTERNATIONAL JOURNAL OF COMPUTERS \& TECHNOLOGY

Vol 12, No.5

editor@cirworld.com

www.cirworld.com, member.cirworld.com 


\section{INTRODUCTION}

The portfolio was originally used by artists to present a set of representative pieces of their work to prospective buyers. It was first applied to the field of education in the early 1980s by Peter Elbow and Pat Belanoff (1986), two professors at Stony Brook University, New York State, as an alternative to standardized tests (Lombardi, 2008). Since then, the portfolio has gained popularity across all education levels, and it now serves a multitude of purposes. A transversal learning tool par excellence, its primary asset is that it can combine a number of educational modes. Thus, in a single package, it can showcase learning progress along the entire academic pathway, with examples from different times (school year, term, cycle) and places (private school, secondary school, university, practicum). As such, the portfolio is one of the rare tools that can provide a tangible demonstration of individual learning trajectories. As a normative tool, it fosters constructive action, because it places the onus on individuals to engage in autonomous learning, a desirable attitude if teachers are to embrace the idea of continuous professional development during their training and throughout their career. The portfolio is therefore a unique and useful tool that can be instrumental in the professional development of preservice teachers.

Against this background, this article presents an overview of the portfolio as support for the professional development of preservice teachers in initial teacher training. We begin by outlining the main types of electronic portfolios, followed by their main functions in initial training programs grouped into four general categories: exposure, reflective, social, and assessment. We then discuss the advantages of the electronic portfolio (hereinafter eportfolio) over the paper portfolio and propose a conceptual framework for eportfolio use to support professional development in the Web 2.0 age. Finally, to provide a concrete example of how the eportfolio can support professional development in preservice teachers, we present Eduportfolio, beginning with the main functions and following with some guidelines for its pedagogical use, including the many ways that Eduportfolio can support professional development.

\section{Main types of eportfolios in teacher education}

According to Meyer, Abrami, Wade, Aslan, and Deault (2010), an eportfolio has three main purposes: support the professional development process, showcase accomplishments and reflections, and assess professional development. Based on these three main purposes, education professors use diverse types of eportolios to train their teaching students:

- Digital archives, where preservice teachers simply deposit works (hereinafter artifacts) related to their training, without providing any added value such as comments or reflections, and without making the content public;

- Learning eportfolios, where preservice teachers "document their journey in becoming a teacher as they select, share, and reflect on artifacts such as educational philosophies, classroom management plans, unit and lesson plans, plans to meet the needs of diverse and special-needs pupils, and video clips of practice teaching" (Strudler \& Wetzel, 2011, p. 162);

- Assessment portfolios - either formative or summative - where preservice teachers must provide artifacts to demonstrate that they meet the assessment criteria of their training program (see Strudler \& Wetzel, 2011, p. 163);

- $\quad$ Hiring eportfolios, where preservice teachers provide artifacts to demonstrate that they meet schools' hiring criteria (see Barrett \& Knezek, 2003)

Hybrid (multipurpose) eportfolios, intended to archive artifacts, produce reflections on these and share them, and assess initial training programs or find a teaching job (see Strudler \& Wetzel, 2011, p. 163).

Each of these five types has specific objectives according to the initial training program. Consequently, the content of an eportfolio will be determined by these objectives (Barrett, 2007). Additionally, the electronic support for the eportfolio can impact its use, giving rise to a variety of eportfolio types ${ }^{1}$, including those hosted by online learning platforms such as Mahara and Blackboard (Clark \& Neumann, 2009), in-house platforms such as Eduportfolio (Karsenti \& Collin, 2010) and EPEARL (Meyer et al., 2010), website hosts such as Google Sites (Zheng, Wang, Liu, \& Zhao, 2009) and blogs (Hughes \& Purnell, 2008), and even social networking sites such as Ning (Malita \& Martin, 2010). Although each support type has its advantages and limitations, we believe that the support type should be able to accommodate purposes beyond the limitations of the university's objectives once the initial training program has been completed. Otherwise, it cannot support the teacher's lifelong professional development.

\section{Main functions of the portfolio in initial teacher training}

In this section, we present the four main functions of the portfolio in initial teacher training: exposure, reflective, social, and assessment.

\section{The exposure function}

In initial training, the portfolio, both the paper and electronic version, can be used for exposure in various ways. On the one hand, once students have completed their initial training program and obtained their teaching diploma, they can use the portfolio to help find a teaching job (Kitchenham, 2008; Mosely, 2004-2005; Strawhecker, Messersmith, \& Balcom, 2007-2008; Withworth, Deering, Hardy, \& Jones, 2011). For example, Kitchenham (2008) found that many preservice

\footnotetext{
${ }^{1}$ For an extensive description of eportfolio types, see Barrett's categories of eportfolio tools: http://electronicportfolios.com/categories.html.
} 
teachers in Canada said that their portfolios turned out to be "major contributors to their being hired" (p. 143). On the other hand, from interviews with 37 public and private school principals in the USA, Strawhecker et al. (2007-2008) observed that the principals generally felt that the portfolios gave them a better idea of the candidates' teaching and organizational skills. Nevertheless, Whitworth et al. (2011) stressed that the portfolio is only one tool among many when it comes to hiring new teachers. We should also keep in mind that principals are often sceptical about the authenticity of portfolio content, particularly when artifacts are intended for distribution, and they may feel it a waste of time to consult portfolios. Notwithstanding, Whitworth et al. contend that even when employees do not look at portfolios, the effort of developing them is an excellent way for preservice teachers to prepare for hiring interviews. Furthermore, a portfolio intended to shed positive light on the candidate can benefit from public distribution, with either universal Web access or limited access (e.g., with password protection, for the school principal's eyes only). Theoretically, the first option allows reaching more potentia employees, because not only is the content widely accessible, it is also indexed by search engines. The second option allows preservice teachers to target their exposure to desirable employers and to retain more control over their professional information.

In addition, preservice teachers can use the portfolio to showcase their educational accomplishments during the training program. These must be judiciously selected to demonstrate the progress made in terms of professional development, not only to instructors and peers, but more importantly, to oneself. Strudler and Wetzel (2011) noted that one of the advantages of selective exposure was that preservice teachers are more motivated to use the portfolio when they can choose the works that best represent their knowledge and accomplishments.

\section{The reflective function}

In initial training programs, the portfolio is frequently used to support reflective practice in students (Strudler \& Wetzel, 2011). Reflective practice is a mandatory professional competency in many initial teacher training programs, and is considered an important component of the standards of the National Council for the Accreditation of Teacher Education in the USA (Ostorga, 2006). The portfolio may therefore be viewed as a tool that enables students to take a step back and adopt an objective, critical attitude toward their development of competencies and professional practices (Gresso \& Lomicka, 1999). On this topic, Lin (2008) noted that the reflective practice that the portfolio allows "not only provides more information and insight on the learner's performance, but also helps learners to make connections with prior learning, and to transform previous learning into active and authentic knowledge" (p. 199). It is therefore arguable that the reflective function of the portfolio is a determinant for the quality of professional development in preservice teachers, and that this function distinguishes it from the archival portfolio, which simply contains academic assignments. Accordingly, to encourage preservice teachers to reflect on their professional practice, many authors, including Bloom and Bacon (1995), recommend organizing the portfolio according to the required competencies. Under this approach, preservice teachers associate the materials they select for their portfolio with specific professional competencies. This pushes them to clarify the meaning of the required professional competencies and to reflect on the degree to which they have developed these competencies as well as the materials that would best represent them. The reflective function of the portfolio is therefore based on a "reflective triangulation", which involves thoughtful consideration of the required professional competencies, awareness of the degree to which these competencies have been developed, and selecting the materials that would most aptly and appropriately represent these.

In addition to this triangulation, the reflective function is manifest in the associated writing process (Minuth, 1999). As Imhoff and Picard (2009) explain, "To keep and administer a portfolio requires reflexive writing skills (Eigler, 2005; Lee, 2005), among which may be counted a general sensitivity for critical events, the ability to reflect on one's own role in a conflict, the willingness to accept errors and mistakes as learning opportunities" (p. 153). Thus, developing an eportfolio requires writing the materials, and when writers translate their thoughts into the written word, it helps them extrapolate from their experience, take a step back, and adopt a critical stance. Therefore, writing can help structure thought as the writer seeks to prioritize, classify, and organize ideas. In and of itself, and beyond the portfolio, the act of writing is therefore:

...a tool for developing and refining thought by reason of its primarily (self-) reflective nature. [...] Most importantly, writing allows one to review one's thoughts in order to arrive at increasingly accurate formulations. Writing enables one to entertain judgments, analyze, and synthesize, and communicate the state of a reflection, and it prompts one to engage in an internal process by which knowledge can be developed, clarified, and transmitted. [free translation] (Vanhulle \& Deum, 2006, p. 6-7)

Furthermore, unlike the spoken word, the written word is fixed and enduring. The reflection developed through building a portfolio can be revisited at any time and refined in an ongoing process of knowledge expansion (Bucheton, 2003). Finally, it is worth noting that mentorship and the provision of guidance and support for developing reflective practice through a portfolio are key factors for preservice teachers to fully benefit from the process (Pecheone, Pigg, Chung, \& Souviney, 2005).

\section{The assessment function}

The fourth function is assessment. In this respect, the portfolio is innovative insofar as it enables considering both the outcomes and the process of professional development (Goupil, Petit, \& Pallascio, 1999). The portfolio therefore allows a more "authentic" assessment mode, because it provides a contextualized overview of the student's achievements in terms of professional development, to both professor and student (Bloom \& Bacon, 1995). 
It is important to clarify that when assessing a portfolio, the nature of the portfolio must be taken into account. Because the portfolio is developed progressively and individually over a certain amount of time, it must be assessed as an ongoing process that is both personal and fluid. Moreover, given the personal nature of the content, university professors would gain by assessing it in collaboration with the student, using negotiation and constructive criticism, and keeping in mind the planned sequence of professional development. This is critical so that preservice teachers can grasp that the portfolio is more than a simple "testing tool" that rates their professional development during initial training. In addition, note that the portfolio is not meant to replace other assessment methods that are considered more normative (Goupil et al., 1999).

\section{The social function}

Parallel to the exposure and reflective functions is the social function. Thus, during initial training, and through exchanges with university professors and (more rarely) peers, the portfolio generally encourages interactions concerning professional development issues. From a professorial standpoint, the portfolio is a useful way to supervise preservice teachers, not only during a course, but, if the portfolio is a requirement from the beginning of the program, throughout the initial training program as well. Exchanges may bear on topics such as progress made and challenges met in terms of professional development, strategies to attain set objectives, reasons for selecting material to include in the portfolio, future objectives, and so on.

We should point out that the social function is less predominant in the paper portfolio than in the eportfolio, which makes it easy to distribute and share information (Godwin-Jones, 2008). Formerly viewed exclusively by the university professor and the preservice teacher, the portfolio content may now (although not necessarily) be freely consulted by peers, and more broadly, by anyone on the Internet. When peer exchanges are put to their best use, the portfolio becomes a space for
...the social construction of knowledge, a construction that accompanies the progressive construction of the professional identity. This co-construction of the intern's knowledge and professional identity initially takes place among peers. In accordance with and in opposition to them and their feedback, the intern builds a new professional identity, with a unique set of aptitudes and individual talents. [free translation] (Bucheton, 2003, p. 16)

The ability to consult peers' portfolios and offer comments can foster meetings of the mind, takings of position, and a sense of participation in the collective professional development of future teachers. In sum, Maher and Gerbic (2009) argue that the portfolio, being a "personal" tool, makes a good fit with the new social networking tools, and consequently could be highly relevant for today's youth.

Note also that the social function of the portfolio opens new perspectives for assessment. Thus, the capacity to publish portfolio content means that peers can eventually be incorporated into the assessment process, along with professors. The portfolio also appears to be useful for self-assessment purposes (Jorro, 2006), as it can help both teachers and preservice teachers set future learning goals by reflecting on their learning acquisition and progress (Lin, 2008). However, to be comprehensive and effective, self-assessment needs to be done regularly, and it should be supervised, for instance, through meetings with professors.

As we have seen, the portfolio can be used in a number of ways to foster professional development in initial teacher training. We have grouped these into four main categories: the exposure, reflective, assessment, and social functions. Importantly, however, portfolios are not in and of themselves tools that foster reflective practice. Professors must apply their influence so that students buy into the eportfolio building process. Then, over time, both professors and students can appraise and assess them (Plaisir, Hachey, \& Theilheimer, 2011, p. 162). The reflective function of the eportfolio is also enhanced by the capacity to review and continuously deepen one's reflective thinking, which is limited in the paper portfolio by the paper medium. The social function has certainly been expanded by the evolution of Web 2.0, with its easier distribution and sharing. In addition, the electronic version opens up new assessment possibilities. For instance it allows peer input, which can encourage users to improve the quality of their work and develop problem-solving approaches as part of their professional development (Hung, 2012). And beyond the particular situation of initial teacher training programs, the eportfolio offers further transversal advantages, as shown in the next section.

\section{Advantages of the eportfolio}

Compared to the paper portfolio, the eportfolio has the following advantages:

- Enhanced social function: Because it usually includes a comments function, the eportfolio enables greater communication between students and other parties in the education process (teachers, parents, other students), which provides opportunities for feedback. This enhances the social function of the portfolio, and adds the potential to set up learning communities (Albion, 2008).

- Flexibility of content organization: The eportfolio allows flexible content organization, which in turn fosters portfolio evolution. In other words, learners can adapt their portfolio as they pursue their learning, adding new sections, revising old ones, and so on (Challis, 2005).

- Flexibility of content: The eportfolio also provides flexibility of the content itself. For example, using a computer, the content can be deleted, replaced, cut and pasted, and corrected as desired, without hindering the readability. This flexibility has a significant influence on the reflective process, because learners can 
review their work to their heart's content, publish a number of different versions of the same text, and keep track of their progress over time.

- Enormous storage capacity: The eportfolio typically has enough storage capacity to host a vast number of texts that are nevertheless simple to manage. In contrast, a voluminous paper portfolio would be heavy, unwieldy, and possibly confusing. In this sense, the eportfolio appears to have the long-term advantage.

- Aesthetics: The eportfolio is an aesthetic tool owing to two features that paper portfolios generally lack: (1) first, it usually offers a wide choice of templates, colours and images, for multiple style options; and (2) as mentioned above (content flexibility), writing on a computer produces texts that are uniform and legible, providing consistent readability.

- Accessibility: Once the eportfolio is posted online, it provides universal and immediate access, as long as there is an Internet connection (Challis, 2005). However, the inconvenience here is that, unlike the paper portfolio, the eportfolio requires technological support.

- Development of ICT skills: In order to realize the full benefit of an eportfolio, users must know how to use a variety of digital functions (e.g., online writing, online navigating, uploading documents), such that by using this tool, users will develop their ICT skills (see Kabilan \& Khan, 2012).

In light of this brief overview of the advantages of the eportfolio, we propose a conceptual framework based on recent technological advances in Web 2.0 .

\section{Towards a conceptual framework for the use of the eportfolio to support professional development in the Web 2.0 age}

Our proposed conceptual framework underscores the contributions of the eportfolio to the professional development of preservice teachers. It constitutes a first attempt that merits further investigation. The framework is based largely on the latest technological developments in Web 2.0. The term “Web 2.0" emerged only recently. It was coined by Tim O'Reilly in 2004 and formalized in a subsequent article (O'Reilly, 2005). Wikipedia, ${ }^{2}$ a Web 2.0 production par excellence, defines it as follows:

The term Web 2.0 is associated with web applications that facilitate participatory information sharing, interoperability, user-centered design, and collaboration on the World Wide Web. A Web 2.0 site allows users to interact and collaborate with each other in a social media dialogue as creators (prosumers) of usergenerated content in a virtual community... (Wikipedia, 2012)

This is a departure from Web 1.0, as explained by Franklin and Van Harmelen (2007): "In Web 1.0 a few authors provided content for a wide audience of relatively passive readers. However, in Web 2.0 everyday users of the web use the web as a platform to generate, re-purpose, and consume shared content" (p. 4). Well known Web 2.0 software applications include the blog (text, audio, and/or video), the wiki, tagging, social bookmarking, media sharing, RSS feeds, and syndication (Anderson, 2007; Cych 2006; Depover, Karsenti, \& Komis, 2007). All these applications expand opportunities for Internet exchanges between users, and by the same token, social use of the Web: "With Web 2.0 data sharing the web also becomes a platform for social software that enables groups of users to socialise, collaborate, and work with each other" (Franklin \& Van Harmelen, 2007, p. 4). Furthermore, Maudoodi, Baldwin, and Jones (2012) propose that the advent of cloud computing allows eportfolio users to simplify the ways that they can create, deposit, access, and present their artifacts. They add that this also allows overcoming the limitations of university server-based eportfolio models, for which both preservice teachers and professors must learn how to master a multi-step process in order to get full use out of the site, including structuring, organization, archiving, and transferring files. In short, when incorporating Web 2.0, eportfolio designs should not require users to have programming skills or to be highly tech-savvy. On the other hand, Foti and Ring (2008) feel that the new cloud computing functions render the old eportfolio creation models inadequate for handling new ways of thinking, reflecting, and learning: "While the collect, select, reflect, connect, etc. models used in a pre-Web 2.0 world helped us think about basic tasks in the process, they seem inadequate to describe how students interact with the cloud." For instance, they propose that students will be able to mix and re-mix their artifacts alone or in collaboration (e.g., a Google Drive file), and to use embedding (e.g., YouTube) in their eportfolio. Furthermore, we believe that when eportfolio content, such as a Word document, can be retrieved by descriptive key words, Web 2.0 functionality contributes to eportfolio exposure through more finely tuned search engine indexing. This type of indexing can direct potential employers to a preservice teacher's eportfolio and help get that teacher hired.

From a systems perspective, Web 2.0 tools primarily involve network structures. In this sense, eportfolio use in initial teacher training is fully consistent with the Web 2.0 vision of networking and counterbalance, owing to the group culture that prevails during the program. In both cases, learning (in the broad sense, including professional development) is conceived as a social development process whereby individuals interact with the people in their surroundings (Vygotsky, 1962). On the other hand, the group is generally thought of as an indivisible entity, and belonging to it is an explicit criterion that is limited to certain individuals. As the inverse of the group, the network is not clearly demarcated: no one knows for sure where it begins or ends. In addition, it does not impose a common trajectory for all its members, but instead allows individual trajectories. Importantly, however, these individual trajectories are mutually connected. As

\footnotetext{
${ }^{2}$ http://en.wikipedia.org
} 
support for the individual professional development of each preservice teacher, the eportfolio is situated in a network culture, and not the group culture that has long predominated in the education field (exemplified in the term "class group").

Many studies have shown that teaching is a particularly isolated practice, that there is a gap between prescribed teaching standards and what actually goes on in the classroom, and that this gap first emerges during the initial training program (Evans \& Powell, 2007, p. 200). They further suggest that teacher training programs do not provide many opportunities to work in collaboration, and that academic competitiveness results in individualized teaching practices. Albion (2008) proposes that online learning communities established through eportfolios under initial training programs could provide "a powerful social learning environment that makes efficient use of instructor time and should encourage habits of mind that mitigate against privatization of practice" (p. 195). In sum, given the technical and pedagogical possibilities offered by today's eportfolios, the professional development process of preservice teachers can - and should - change from an individualized process to a collaborative process between individuals, peers, and educators.

\section{Brief presentation of Eduportfolio}

Eduportfolio is an eportfolio that was created in 2007 by Professor Karsenti and his collaborators. It is noteworthy that this tool was developed in continuous interaction with the user community. The process included research phases (e.g., a literature review on the portfolio in education), a needs analysis for education stakeholders (e.g., group interviews, online questionnaire), technical development (computer design), and assessments (e.g., group interviews, online questionnaires, email feedback). This interactive, iterative development process led to the growing popularity of Eduportfolio in educational circles, and today it counts roughly 20,000 users around the world. Eduportfolio is multilingual, and is available in French, English, Spanish, Catalan, Greek, Korean, and Arabic.

To highlight its pedagogical potential, we first explain some of the driving design choices. Eduportfolio emerged from the important distinction between tool design and tool use. Although tools are designed by designers, in the end, the users are those who decide how the tools are used. Accordingly, as the designers of Eduportfolio, we did not want to bias the pedagogical uses that would be made of it. Instead, we felt that educators should determine its relevance according to their own situations and educational goals. We therefore allowed for maximum freedom on the part of educators to choose how they wanted to use Eduportfolio. Consequently, our role as designers was not to determine pedagogical purposes, but to offer a tool with the flexibility to accommodate as many purposes as possible. The result is that there are no predetermined pedagogical uses for Eduportfolio. Instead, it provides the broad flexibility to respond to as many pedagogical objectives that educators can bring to the table. This design choice makes Eduportfolio radically different from other education portfolios (e.g., EPEARL), which have specific, predetermined goals that limit the number of potential uses.

The chief problem with this design, with no predefined purpose, is that the people who use it must clearly understand their own purposes, which may be predetermined. In fact, many studies have underscored that successful eportfolio implementation and user satisfaction depend largely on clarity of purpose (Imhoff \& Picard, 2009; Strudler \& Wetzel, 2005, 2008). Moreover, Granberg (2010) contends that the eportfolio also depends strongly on the educator's understanding of how it will be used and how that understanding will evolve in the minds of its users. In other words, when the eportfolio is part of a system designed to foster interaction between its diverse functions and its users, the original design and purpose cannot but evolve as a result of social construction. And this is precisely what has happened with Eduportfolio, where continuous user feedback has generated both improved and evolving functions. Nevertheless, we are aware that the flexibility of this tool is not a guarantee of its success, which depends more on the quality of its purposes and how these purposes are upheld by the users, and more particularly, by educators.

\section{Overview of potential uses of Eduportfolio as support for the professional development of preservice teachers}

We have presented this overview of Eduportfolio to provide an idea of its potential in terms of flexibility and adaptation for multiple pedagogical purposes and educational situations. Thus, Eduportfolio can support the professional development of preservice teachers in a variety of ways and with a variety of approaches across a variety of training programs. For example, in a 2010 online survey of 403 preservice teachers of French as a second language who had used Eduportfolio as part of their training, $82 \%$ agreed that the mandatory nature of the platform was the strongest motivation for using it compared to using it for professional visibility (45\%), support for reflective practice (35\%), or learning (30\%). Apparently, they used an eportfolio mainly to comply with their professors' instructions. Furthermore, more students perceived the eportfolio as an individual (63\%) rather than a collaborative tool $(39 \%)$, suggesting that they did not fully appropriate the Web 2.0 functions. Perhaps the professors did not provide sufficient instructions for use, which "can be viewed as an unrealized gain in certain learning situations, particularly from a social constructive perspective" (Karsenti \& Collin, 2010 , p. 74). Similarly, Siampou and Komis (2011) administered a questionnaire to 185 preservice teachers in Greece before and after a course on Eduportfolio use. Most respondents felt that the tool promoted learning and self-assessment more than peer contact. Thus, few respondents had visited or commented on their peers' showcases, suggesting that the mere availability of online interactivity on Eduportfolio does not guarantee its use. Furthermore, it would seem that the tool should be simplified, because one-fourth of the surveyed preservice teachers reported that they had technical problems using it. In addition, one-fourth of the respondents said that they did not want their peers to comment on their work, so as to avoid embarrassment. This kind of attitude does not foster peer-to-peer interactivity. Furthermore, only one-third of the respondents said that they planned to continue using Eduportfolio in order to add content to their eportfolios or to exchange ideas with their colleagues, suggesting that this tool needs further improvement in terms of both technical aspects and user instructions. 
We should also point out that the academic value of the portfolio varies across programs. Sometimes the portfolio is maintained for specific assessment purposes (e.g., a term credit), whereas at other times the portfolio is incorporated into a more global assessment (e.g., practicum assessment, assessment of a course involving Eduportfolio). The ways in which time and space are integrated also vary. Whereas some programs use Eduportfolio in a cross-disciplinary manner and for longer durations (e.g., throughout the entire program), thereby exploiting its combinatorial potential, others use it at specific times (e.g., during the practicum) or for specific courses (e.g., a course on the pedagogical integration of ICT). With respect to the Eduportfolio structure, professors can design a predetermined structure that preservice teachers must retain throughout the program. In this case, the showcases are organized according to specific pedagogical objectives and distributed to the preservice teachers "as is." Or, under a more developmentalist vision, the structure can be left open to allow room for individual development, with only a starting point provided. In this case, the preservice teachers would be given some general guidelines and objectives, but they would design their portfolio structures to represent their own professional development. Supervision is another variable in the use of Eduportfolio. Some programs involve human supervision (e.g., university professors, practicum supervisors, and less frequently, peers), whereas in others, supervision is done with tools such as monitoring or self-assessment sheets. A further variable is the number of individuals that contribute to support the professional development of preservice teachers. With its advanced social functions, Eduportfolio can create a collective space by fostering interactions between education stakeholders. In other programs, keeping a portfolio is viewed as an individual pursuit, and preservice teachers do not require external input to develop their portfolio.

Let us recall that this is not an exhaustive list of variables. We simply wanted to provide an overview of the many ways that educators can take advantage of Eduportfolio's flexibility to incorporate it into training programs. We also wanted to provide some concrete examples of how Eduportfolio can be used to support professional development in preservice teachers.

Additionally, we wanted to underscore that fact that the rapid development of Web 2.0 functions has compelled us to rethink and improve the Eduportfolio design, notably by simplifying the interface and the setting options, and by enhancing the drag and drop feature to bring it in line with the more user-friendly style of website hosts such as Weebly ${ }^{3}$.

\section{Conclusion}

The aim of this article was to provide an overview of the portfolio as support for professional development in preservice teachers in initial training programs. We began by presenting the four main functions of the portfolio as it is used in initial teacher training: exposure, reflective, assessment, and social. We then outlined the advantages of the electronic over the paper portfolio and proposed our conceptual framework for eportfolio use to support professional development in the Web 2.0 age. This conceptual framework is based largely on the transition from a group culture to a network culture, where the eportfolio is situated as support for professional development. To provide a concrete example, we then presented Eduportfolio, a highly flexible eportfolio that is currently used in many initial teacher training programs. After describing some of its functions, we listed some variables for the pedagogical use of this tool along with some of the many ways that Eduportfolio can be used to support professional development in preservice teachers.

More research is needed to deepen our understanding of how the eportfolio can contribute to professional development in preservice teachers. Studies by authors such as Abrami and Barrett (2005), LaCour (2005), and Godwin-Jones (2008) and the ongoing empirical studies on Eduportfolio would be relevant starting points for determining directions for future empirical research.

\section{REFERENCES}

[1] Abrami, P. C., \& Barrett, H. C. (2005). Directions for research and development on electronic portfolios. Canadian Journal of Learning and Technology, 31(3). Retrieved from http://www.cjlt.ca/index.php/cjlt/article/view/92

[2] Albion, P. (2008). Web 2.0 in teacher education: Two imperatives for action. Computers in the Schools, 25(3), 181198. doi:10.1080/07380560802368173

[3] Anderson, P. (2007). What is Web 2.0? Ideas, technologies and implications for education. (Report prepared for The Joint Information Systems Committee). Retrieved from www.jisc.ac.uk/media/documents/techwatch/tsw0701b.pdf

[4] Barrett, H. C. (2007). Researching electronic portfolios and learner engagement: The REFLECT Initiative. Journal of Adolescent \& Adult Literacy, 50(6), 436-449. doi:10.1598/JAAL.50.6.2

[5] Barrett, H. C., \& Knezek, D. (2003, April). e-Portfolios: Issues in assessment, accountability and preservice teacher preparation. Paper presented at the annual meeting of the American Educational Research Association, Chicago, IL.

[6] Bloom, L., \& Bacon, E. (1995). Using portfolios for individual learning and assessment. Teacher Education and Special Education, 18(1), 1-9. doi:10.1177/088840649501800102

[7] Bucheton, D. (2003). Du portfolio au dossier professionnel: éléments de réflexion. Retrieved from http://probo.free.fr/textes amis/portfolio bucheton.pdf

[8] Challis, D. (2005). Towards the mature ePortfolio: Some implications for higher education. Canadian Journal of Learning and Technology, 31(3). Retrieved from http://cjlt.csj.ualberta.ca/index.php/cjlt/article/view/93/87

\footnotetext{
${ }^{3}$ http://www.weebly.com
} 
[9] Clark, W., \& Neumann, T. (2009). ePortfolios: Models and implementation. WLE Centre Occasional paper in workbased learning

5.

Retrieved

from http://www.wlecentre.ac.uk/cms/files/occasionalpapers/op5_eportfolios_models_and_implementation.pdf

[10] Cych, L. (2006). Social networks. In Emerging technologies for learning (pp. 32-41). Coventry, U.K.: Becta.

[11] Depover, C., Karsenti, T., \& Komis, V. (2007). Enseigner avec les technologies: favoriser les apprentissages, développer des compétences. Québec, QC: Presses de l'Université du Québec.

[12] Elbow, P., \& Belanoff, P. (1986). Portfolios as a substitute for proficiency examinations. College Composition and Communication, 37(3), 336-339.

[13] Evans, M. A., \& Powell, A. (2007). Conceptual and practical issues related to the design for and sustainability of communities of practice: The case of e- portfolio use in preservice teacher training. Technology, Pedagogy and Education, 16(2), 199-214. doi:10.1080/14759390701406810

[14] Foti, S., \& Ring, G. L. (2008). From ePortfolios to iPortfolios: The find, refine, design, and bind model. Canadian Journal of Learning and Technology, 34(3). Retrieved from http://cjlt.csj.ualberta.ca/index.php/cjlt/article/view/506

[15] Franklin, T., \& Van Harmelen, M. (2007). Web 2.0 for content for learning and teaching in higher education (Report prepared for The Joint Information Systems Committee). Retrieved from http://www.jisc.ac.uk/publications/publications/web2andpolicyreport.aspx

[16] Godwin-Jones, R. (2008). Emerging technologies. Web-writing 2.0: Enabling, documenting, and assessing writing online. Language Learning \& Technology, 12(2), 7-13. Retrieved from http://lt.msu.edu/vol12num2/emerging.pdf

[17] Goupil, G., Petit, E.-L., \& Pallascio M.-C. (1998). Le portfolio: un pas vers une évaluation plus "authentique" orientée vers l'acquisition de compétences. Revue québécoise de psychologie, 19(2), 167-181.

[18] Granberg, C. (2010). E- portfolios in teacher education 2002-2009: The social construction of discourse, design and dissemination. European Journal of Teacher Education, 33(3), 309-322. doi:10.1080/02619761003767882

[19] Gresso, H., \& Lomicka, L. (1999). Le portfolio: une méthode active, constructive, réflective. Tracer, 15, 23-30.

[20] Hughes, J., \& Purnell, E. (2008). Blogging for beginners? Using blogs and eportfolios in teacher education. In Proceedings of the $6^{\text {th }}$ International Conference on Networked Learning (pp. 144-153). Retrieved from http://www.networkedlearningconference.org.uk/past/nlc2008/abstracts/Hughes.htm

[21] Hung, S.-T. A. (2012). A washback study on e-portfolio assessment in an English as a Foreign Language teacher preparation program. Computer Assisted Language Learning, 25(1), 21-36. doi:10.1080/09588221.2010.551756

[22] Imhof, M., \& Picard, C. (2009). Views on using portfolio in teacher education. Teaching and Teacher Education, 25(1), 149-154. doi:10.1016/j.tate.2008.08.001

[23] Jorro A. (2006). Les formes de la reconnaissance professionnelle dans la démarche du portfolio. In G. Figari, P. Rodrigues, M. P. Alves, \& P. Valois (Eds.), Évaluation et compétences et apprentissage expérientiels: savoirs, modèles et méthode (pp. 143-151). Lisbon, Portugal: Educa.

[24] Kabilan, M. K., \& Khan, M. A. (2012). Assessing pre-service English language teachers' learning using e-portfolios: Benefits, challenges and competencies gained. Computers \& Education, 58(4), 1007-1020. doi:10.1016/j.compedu.2011.11.011

[25] Karsenti, T., \& Collin, S. (2010). The Eportfolio: How can it be used in French as a second language teaching and Learning? International Journal of Technologies in Higher Education, 7(1), 68-75. Retrieved from http://www.ritpu.org/spip.php?article177

[26] Kitchenham, A. (2008). E-Portfolios in teacher education: The UNBC experience. Collected Essays on Learning and Teaching, 1, 138-144. Retrieved from http://ojs.uwindsor.ca/ojs/leddy/index.php/CELT/article/view/3194

[27] LaCour, S. (2005). The future of integration, personalization, and ePortfolio technologies. Innovate, 1(4).

[28] Lin, Q. (2008). Preservice teachers' learning experiences of constructing e-portfolios online. The Internet and Higher Education, 11(3-4), 194-200. doi:10.1016/j.iheduc.2008.07.002

[29] Lombardi, J. (2008). To portfolio or not to portfolio: Helpful or hyped? College Teaching, 56(1), 7-10. doi:10.3200/CTCH.56.1.7-10

[30] Maher, M., \& Gerbic, P. (2009). E-portfolios as a pedagogical device in primary teacher education: The AUT University experience. Australian Journal of Teacher Education, 34(5). Retrieved from http://ro.ecu.edu.au/ajte/vol34/iss5/4/

[31] Malita, L., \& Martin, C. (2010). Digital Storytelling as web passport to success in the $21^{\text {st }}$ Century. Procedia-Social and Behavioral Sciences, 2(2), 3060-3064. doi:10.1016/j.sbspro.2010.03.465 
[32] Maudoodi, R., Baldwin, B., \& Jones, C. (2012). Preservice teachers e-portfolio evolving in a Web 2.0 world. In P. Resta (Ed.), Proceedings of Society for Information Technology \& Teacher Education International Conference 2012 (pp. 3930-3933). Chesapeake, VA: AACE.

[33] Meyer, E., Abrami, P. C., Wade, C. A., Aslan, O., \& Deault, L. (2010). Improving literacy and metacognition with electronic portfolios: Teaching and learning with ePEARL. Computers \& Education, 55(1), 84-91. doi:10.1016/j.compedu.2009.12.005

[34] Minuth, C. (1999). Écrire pour construire une réflexion sur les apprentissages. Tracer, 15, 11-22.

[35] Mosely, C. (2004-2005). The value of professional teaching portfolios to prospective employers: School administrators' views. The Professional Educator, 27(1-2), 58-72. Retrieved from http://eric.ed.gov/?id=EJ728482

[36] O'Reilly, T. (2005). What is Web 2.0: Design patterns and business models for the next generation of software. Retrieved from http://oreilly.com/web2/archive/what-is-web-20.html

[37] Ostorga, A. N. (2006). Developing teachers who are reflective practitioners: A complex process. Issues in Teacher Education, 15(2), 5-20. Retrieved from http://eric.ed.gov/?id=EJ796265

[38] Pecheone, R., Pigg, M., Chung, R., \& Souviney, R. (2005). Performance assessment and electronic portfolios: Their effect on teacher learning and education. The Clearing House, 78(4), 164-176. doi:10.3200/TCHS.78.4.164-176

[39] Plaisir, J. Y., Hachey, A. C., \& Theilheimer, R. (2011). The portfolios, our role: Examining a community college teacher education digital portfolio program from the students' perspective. Journal of Early Childhood Teacher Education, 32(2), 159-175. doi:10.1080/10901027.2011.572231

[40] Shepherd, C. E., \& Hannafin, M. J. (2008). Examining preservice teacher inquiry through video-based, formative assessment e-portfolios. Journal of Computing in Teacher Education, 25(1), 31-37. Retrieved from http://eric.ed.gov/?id=EJ834092

[41] Siampou, F., \& Komis, V. (2011). Enseigner les fonctionnalités et les usages des e-portfolios: une étude basée sur les conceptions des futurs enseignants. In G.-L. Baron, E. Bruillard, \& V. Komis (Eds.), Actes du $4^{e}$ colloque international DIDAPRO (pp. 73-77). Athens, Greece: New Technologies. Retrieved from http://halshs.archives-ouvertes.fr/edutice00690090/

[42] Strawhecker, J., Messersmith, K., \& Balcom, A. (2007-2008). The role of electronic portfolios in the hiring of K-12 teachers. Journal of Computing in Teacher Education, 24(2), 65-71. Retrieved from http://eric.ed.gov/?id=EJ834060

[43] Strudler, N., \& Wetzel, K. (2005). The diffusion of electronic portfolios in teacher education: Issues of initiation and implementation. Journal of Research on Technology in Education, 37(4), 411-433. Retrieved from http://eric.ed.gov/?id=EJ690981

[44] Strudler, N., \& Wetzel, K. (2008). Costs and benefits of electronic portfolios in teacher education: Faculty perspectives. Journal of Computing in Teacher Education, 24(4), 135-142.

[45] Strudler, N., \& Wetzel, K. (2011). Electronic portfolios in teacher education: Forging a middle ground. Journal of Research on Technology in Education, 44(2), 161-173. Retrieved from http://tl.unlv.edu/ strudler/StrudlerWetzel11.pdf

[46] Vanhulle, S., \& Deum, M. (2006). L'écriture réflexive en formation initiale d'enseignants: entre réconciliation avec l'écrit et apprentissage de la rigueur conceptuelle. Langage et pratiques, 37, 6-19. Retrieved from http://orbi.ulg.ac.be/handle/2268/92816

[47] Vygotsky, L. S. (1962). Thought and language. Cambridge, MA: MIT Press.

[48] Web 2.0. (2012, February 3). In Wikipedia, The Free Encyclopedia. Retrieved September 21, 2013, from http://en.wikipedia.org/w/index.php?title=Web_2.0\&oldid=474716075

[49] Whitworth, J., Deeing, T., Hardy, S., \& Jones, S. (2011). Perceptions regarding the efficacy and use of professional portfolios in the employment of teachers. International Journal of ePortfolio, 1(1), 95-106. Retrieved from http://www.theijep.com/pdf//JEP36.pdf

[50] Zheng, W., Wang, F., Liu, Z., \& Zhao, C. (2009). Construction and application of instructional E-Portfolio system with Web 2.0 and Google services. In Proceedings of the $1^{\text {st }}$ International Conference on Information Science and Engineering (pp. 3265-3268). doi:10.1109/ICISE.2009.423 


\section{ISSN 2277-3061}

\section{Author' biography with Photo}

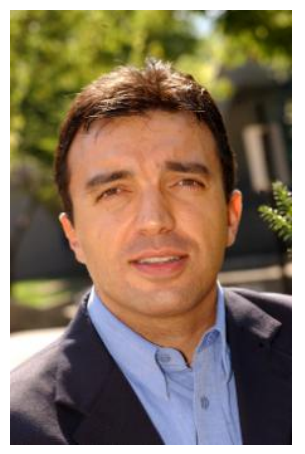

Thierry Karsenti, M.A., M.Ed., Ph.D. is Director of the Centre de recherche interuniversitaire sur la formation et la profession enseignante (CRIFPE) (Interuniversity research centre on education and the teaching profession. Besides holding the Canada Research Chair on Technologies in Education. Thierry Karsenti is also a Full Professor at the University of Montreal 